\title{
Steering System Kinematic and Steady-State Cornering Analysesof the ITS Electric Car
}

\author{
Unggul Wasiwitono $^{1}$, Indra Sidarta ${ }^{1}$, Agus Sigit Pramono ${ }^{1}$, Sutikno $^{1}$, and Alief Wikarta ${ }^{1}$
}

\begin{abstract}
Steering linkages play an important role in maneuvering of cars. In order to provide pure rolling of the road wheels and to reduce wear of the tires, the steering linkage must be able to turn the wheels such that their axis intersection point lies on the rear wheel axis. This condition is known as the Ackermann condition. However, in reality, Ackermann condition is difficult to satisfy for every cornering radius. The only effort we can do is to synthesize the linkage so that the Ackermann condition is satisfied for any turning radius as closely as possible. Hence, an appropriate kinematic model of the steering linkage is essential. The purpose of this research is to analyze the rack and pinion steering linkage for the ITS electric car prototype. From this analysis, the information on the steering linkage dimension and the placement of the steering linkage that give minimum steering error can be obtained. The steering error is defined as the difference between the actual angle made by the outer front wheel during steering maneuvers and the correct angle for the same wheel based on the Ackerman principle. In addition, the steady-state cornering behavior analysis is also conducted. From this analysis, the information of the center of gravity location that give better cornering characteristics can be obtained. Therefore, these analyses help and can be used as starting point to design the chassis and cabin for the ITS electric car prototype.
\end{abstract}

Keywords —steering linkage, rack and pinion, kinematic analysis, steering error, steady-state cornering.

\section{INTRODUCTION}

S teering linkages play an important role in maneuvering of cars. Among the steering linkages, rack and pinion steering (RPS) linkage is the most widely used in passenger cars. The advantages of rack and pinion steering system over the others are 1) simple construction; 2) economical and uncomplicated to manufacture; 3) compact and easy to operate [3]. The rack and pinion steering system consists of two steering arms, two tie rods, and a rack, as shown in Figure 1.

In order to provide pure rolling and to reduce wear of the tires, a steering linkage must be able to maneuver the vehicle so that it follows the Ackermann principle, cornering and free from lateral inertia forces, the line drawn from the center of the wheels should meet at the center of bend, i.e., point $\mathrm{O}$ of Figure 2. Referring to Figure 2, the relation between the inner wheel angle, $\delta \_\mathrm{i}$, and the outer wheel angle according to Ackerman

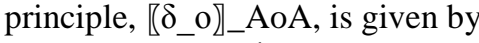

$\boldsymbol{\delta}_{\mathbf{o}_{A}}=\tan ^{-1} \frac{1}{\cot \delta_{i}+\frac{W_{t}}{W_{b}}}$

where W_t is wheel track andW_b is wheel base.

In reality, condition in Eq. (1) is difficult to satisfy for every cornering radius. The only effort we can do is to synthesize the linkage so that the Ackermann condition is satisfied for any turning radius as closely as possible. Hence, an appropriate kinematic model of the steering linkage is essential. Steering linkages have received a lot of attention from the kinematics point of view because of its influence on the Ackermann error [4]. Less attention is paid to its dynamics apparently caused by the fact that the pinion rotates at low speed, typically 10-15 rpm [1].

${ }^{1}$ Unggul Wasiwitono, Indra Sidarta, Agus Sigit Pramono, Sutikno, and Alief Wikarta are with Department of Mechanical Engineering, Faculty of Industrial Technology, Institut Teknologi Sepuluh Nopember, Surabaya, 60111, Indonesia.
Real steering mechanisms are complex spatial linkages. However, the kingpin inclination and caster angles that provide compliance to the steering linkage with the suspension system have little influence on the motion transmission of the steering linkage [4]. As a result, the real rack and pinion steering linkage, which is spatial in nature, can be modeled as a planar linkage for the investigation of Ackermann condition. Therefore, by neglected the kingpin inclination and caster angle, in this study, the steering linkage of a vehicle is considered as a planar linkage. Such a simplification of the steering system has been also used by other researchers, e.g. ([4]; [2]).

The other important characteristic of vehicle is the vehicle characteristic in steady-state cornering. Under normal conditions, a vehicle at constant speed and fixed front steering angle will make a steady circular motion with a constant radius of curvature. This is called steady state cornering. The fundamental characteristic of vehicle motion can be understood by understanding the vehicle characteristic in steady-state cornering.A simplified bicycle model, which is also known as the single-track model, is convenient for the theoretical analysis of vehicle cornering characteristic [6].

The purpose of this research is to analyse cinematically the rack and pinion steering linkage. From this analysis, the information on the steering linkage dimension and the placement of the steering linkage that give minimum steering error can be obtained. The steering error is defined as the difference between the actual angle made by the outer front wheel during steering maneuvers and the correct angle for the same wheel based on the Ackerman principle. In addition, the effect of the center of gravity location on the steady-state cornering characteristic of the ITS electric car is also investigated. This analysis helps and can be used as starting point to design the chassis and cabin for the ITS electric car.

\section{METHOD}

The side take-off configuration of the steering linkage, shown in Figure 1, is more common in passenger cars. Let redraw the side take-off steering linkage for 
kinematic analysis as shown in Figure 3(a). These linkages noted $C_{l} B_{l} A_{l} A_{r} B_{r} C_{r}$ has an infinite number of cognates [4], meaning that the input-output link behaviors of all the cognate linkages are same. Further, the steering linkage shown in Figure 3(a) can be represented as shown in Figure 3(b) which is the cognate of that shown in Figure 3(a). Moreover, $l_{1}$ and $l_{4}$ denote the steering arms of length $l_{a}$, whereas $l_{2}$ and $l_{3}$ represent tie-rods of length $l_{t}$. The length of $w_{t}$ is defined as

$w_{t}=W_{t}-L_{r}$

where $L_{r}$ is length of the rack. Define $k_{l}=\frac{w_{t}}{2}+s$ and $k_{r}=\frac{w_{t}}{2}-s$ with $s$ is the rack displacement, from Figure 3(b)

$$
\begin{aligned}
& l_{1} \cos \theta_{1}+l_{2} \cos \theta_{2}=k_{l} \\
& l_{1} \sin \theta_{1}+l_{2} \sin \theta_{2}=h \\
& l_{4} \cos \theta_{4}+l_{3} \cos \theta_{3}=k_{r} \\
& l_{4} \sin \theta_{4}+l_{3} \sin \theta_{3}=h
\end{aligned}
$$

The equations (3) to (6) can be written as

$l_{2} \cos \theta_{2}=k_{l}-l_{1} \cos \theta_{1}$

$l_{2} \sin \theta_{2}=h-l_{1} \sin \theta_{1}$

$l_{3} \cos \theta_{3}=k_{r}-l_{4} \cos \theta_{4}$

$l_{3} \sin \theta_{3}=h-l_{4} \sin \theta_{4}$

By squaring and summation in Eqs. (7) and (8) we get $l_{2}^{2}=k_{l}^{2}+h^{2}+l_{1}^{2}-2 k_{l} l_{1} \cos \theta_{1}-2 h l_{1} \sin \theta_{1}$

(10)

Considering $A_{l}=2 k_{l} l_{1}, B_{l}=-2 h l_{1}$, and $C_{l}=k_{l}^{2}+$ $h^{2}+l_{1}^{2}-l_{2}^{2}$, Eq. (11) can be written as

$A_{l} \cos \theta_{1}+B_{l} \sin \theta_{1}+C_{l}=0$

To solve Eq. (12) the trigonometric half-angle identities (Waldron and Kinzel, 2004) is used and then simplifying gives

$A_{l}\left(1-t_{l}^{2}\right)+B_{l}\left(2 t_{l}\right)+C_{l}\left(1+t_{l}^{2}\right)=0$

where $t_{l}=\tan \frac{\theta_{1}}{2}$. Further simplification gives

$\left(C_{l}-A_{l}\right) t_{l}^{2}+2 B_{l} t_{l}+\left(A_{l}+C_{l}\right)=0$

Solving for $t_{l}$ gives

$t_{l}=\frac{-B_{l} \pm \sqrt{B_{l}^{2}-C_{l}^{2}+A_{l}^{2}}}{C_{l}-A_{l}}$

and

$\theta_{l}=\theta_{1}=2 \tan ^{-1} t_{l}$

Because $\tan ^{-1} t_{l}$ has a valid range values $-\pi / 2 \leq$ $\tan ^{-1} t_{l} \leq \pi / 2, \theta_{l}$ will have the range $-\pi \leq \theta_{l} \leq \pi$. Typically, there are two solution for $\theta_{l}$ and they are both valid. These correspond to the two assembly modes. Therefore, we need to pick the corresponding desired mode. Using the same method, we obtain

$t_{r}=\frac{-B_{r} \pm \sqrt{B_{r}^{2}-C_{r}^{2}+A_{r}^{2}}}{C_{r}-A_{r}}$

and

$\theta_{r}=\theta_{4}=2 \tan ^{-1} t_{r}$

where $A_{r}=2 k_{r} l_{4}, B_{r}=-2 h l_{4}$, and $C_{r}=k_{r}^{2}+h^{2}+$ $l_{4}^{2}-l_{3}^{2}$.

\section{RESULT AND DISCUSSION}

The Under normal conditions, a vehicle at constant speed and fixed front steering angle will make a steady circular motion with a constant radius of curvature. This is called steady state cornering. The fundamental characteristic of vehicle motion can be understood by understanding the vehicle characteristic in steady-state cornering. Using bicycle model [6], the side-slip angle $\beta$, the yaw rate $r$ as function of vehicle speed and steering angle are given by

$$
\begin{aligned}
& \boldsymbol{\beta}=\left(\frac{1-\frac{m l_{f}}{2 W_{b} l_{r} K_{r}} V^{2}}{1-\frac{m\left(l_{f} K_{f}-l_{r} K_{r}\right)}{2 l^{2} K_{f} K_{r}} V^{2}}\right) \frac{l_{r}}{W_{b}} \delta \\
& r=\frac{V}{\left(1-\frac{m\left(l_{f} K_{f}-l_{r} K_{r}\right)}{2 l^{2} K_{f} K_{r}} V^{2}\right) W_{b}} \delta
\end{aligned}
$$

where $K_{f}$ and $K_{r}$ are the cornering stiffness of the front and rear wheels, respectively. If the vehicle is traveling with a constant speed, $V$, and the yaw velocity is $r$, the radius of the steady-state cornering, $\rho$, is

$\rho=\frac{V}{r}=\left(1-\frac{m\left(l_{f} K_{f}-l_{r} K_{r}\right)}{2 l^{2} K_{f} K_{r}} V^{2}\right) \frac{W_{b}}{\delta}$

Eq. (21) shows how the turning radius $\rho$, changes with velocity $V$ is affected by the sign of $l_{f} K_{f}-l_{r} K_{r}$.

\section{A. Kinematic Analysis}

The purpose of the current study is to analyze kinematically the rack and pinion steering linkage and to findthe information on the steering linkage dimension and the placement of rack that give minimum steering error. The initial design parameters are listed in Table 1. The steering error is defined as [4].

$S E=\left|\delta_{o_{A}}-\delta_{o}\right| S E=\left|\delta_{o_{A}}-\delta_{o}\right|$

where $\delta_{o}$ is the actual angle made by the outer front wheel during steering maneuver and $\delta_{o_{A}}$ is the correct angle for the same wheel based on the Ackermann principle given by Eq. 1 . However, the angle $\theta_{l}$ and $\theta_{r}$ obtained from Eqs 16 and 18, are not the wheel angles. Define the condition for the wheels at the straight position as $\delta_{l}=\delta_{r}=0$ and for the steering arms angle as $\theta_{l 0}, \theta_{r 0}$, then we have the following relation

$\boldsymbol{\delta}_{l}=\boldsymbol{\theta}_{l}-\boldsymbol{\theta}_{l 0}$

$\boldsymbol{\delta}_{r}=\boldsymbol{\theta}_{r}-\boldsymbol{\theta}_{r 0}$

First, let analyze the effect of the rack placement $h$ on the minimum turning radius and the steering error. In this case, the steering arm length is fixed. Therefore, to maintain the wheel angles unchanged for straight condition, we need to adjust the length of tie-rod. Based on Eq. 11. Figure 4 shows the minimum turning radius for different values of $h$. It can be seen that by moving the rack closer to the front wheel axis, we obtain smaller turning radius. However, this condition is not always true for steering error, as shown in Figure5. We obtain minimum steering error for $1.5<h<3 \mathrm{~cm}$ in front of the front wheel axis.

Next, let study the effect of steering arm length on the steering error. The same as the previous case, we use Eq. 11 to find the length of tie-rod when the steering arm length is varied. In this case the rack position $h$ is fixed. Figure6 show the steering error for varied value of steering arm length with the value of $h=2 \mathrm{~cm}$ which represent the good rack placement from aforementioned analysis, respectively. It can be seen from Figure6 that 
the minimum steering error is obtained for the steering arm length around $12.5 \mathrm{~cm}$

\section{B. Steady-State Cornering and Steer Characteristic}

Based on Eq. 21, the changes in turning radius is affected by the sign of $l_{f} K_{f}-l_{r} K_{r}$. There are 3 conditions related to this:

1) $l_{f} K_{f}-l_{r} K_{r}=0$, the turning radius has a constant value at any vehicle speed. This characteristic is called neutral-steer (NS).

2) $l_{f} K_{f}-l_{r} K_{r}<0$, the vehicle turning radius increases with increasing vehicle speed. This characteristic is called under-steer (US).

3) $l_{f} K_{f}-l_{r} K_{r}<0$, the vehicle turning radius decreases with increasing vehicle speed. This characteristic is called over-steer (OS).

Figure 7 shows the turning radius of the ITS electric car for different center of gravity (CG) location. The center of gravity is measured from the front wheel axes. It can be seen that the $\mathrm{CG}$ location at around $1.3 \mathrm{~m}$ from the front wheel axis will give neutral steer characteristic. The farther the distance of CG from the front wheel axis will give over-steer characteristic.

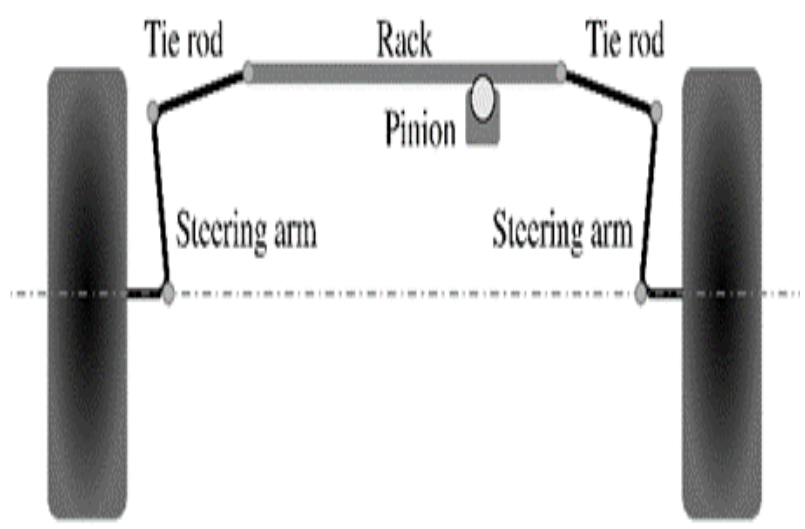

Figure 1. Rack and Pinion steering system configuration

\section{CONCLUSION}

From the analysis, it is found that placing the rack closer to wheels axis will reduce the turning radius of the vehicle. Moreover, by placing the rack around $1.5-3 \mathrm{~cm}$ in front of wheel axis will gives minimum steering error. Analyzing the effect of steering arm length, it is found that the steering arm length that give minimum steering error is around $12.5 \mathrm{~cm}$. For the steady-state cornering, the location of center of gravity that will give neutral steer characteristic is around $1.3 \mathrm{~m}$ from the front wheel axes.

\section{REFERENCES}

[1] R. Hanzaki, S. K. Saha and P. M. Rao, Modeling of a Rack and Pinion Steering Linkage Using Multibody Dynamics, Besancon (France): 12tg IFToMM World Congress, June 18-1-21, 2007.

[2] A. R. Hanzaki, P. M. Rao and S. K. Saha, Kinematic and Sensitivity Analysis and Optimization of Planar Rack and Pinion Steering Linkage, Mechanism and Machine, 44:42-56, 2009.

[3] H. Reimpell, H. Stoll and J. W. Betzler, The Automotive Chassis: Engineering Principle, Butterworth Heinemann, 2002.

[4] P. A. Simionescu and M. R. Smith, "Initial Estimates in the Design of Rack and Pinion Steering Linkages," ASME Journal of Mechanical Design, vol. 122(2), pp. 194-200, 2000.

[5] K. J. Waldron and G. L. Kinzel, Kinematics, Dynamics and Design of Machinery, John Wiley \& Sons, Inc, 2004.

[6] M. Abe, "Vehicle Handling Dynamics: Theory and Application," Butterworth-Heinemann, pp. pp.60-90, 2009.

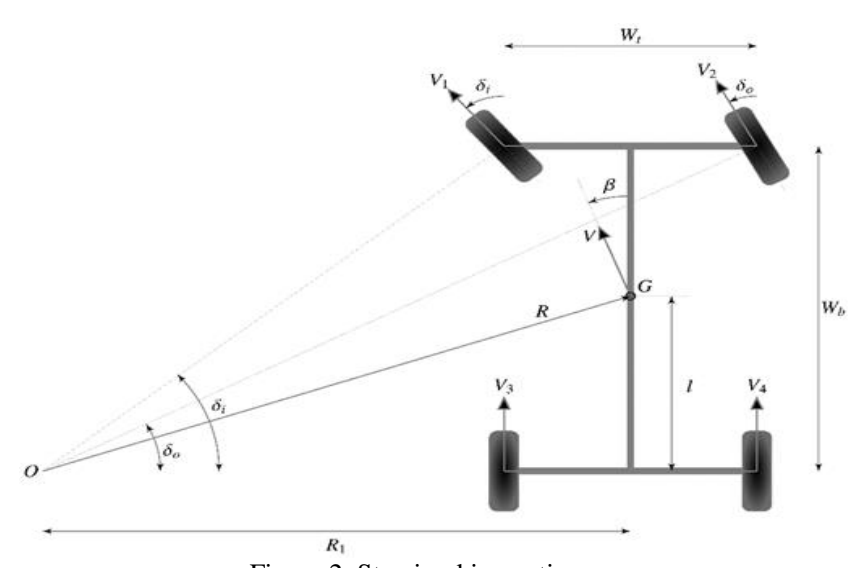

Figure 2. Steering kinematics

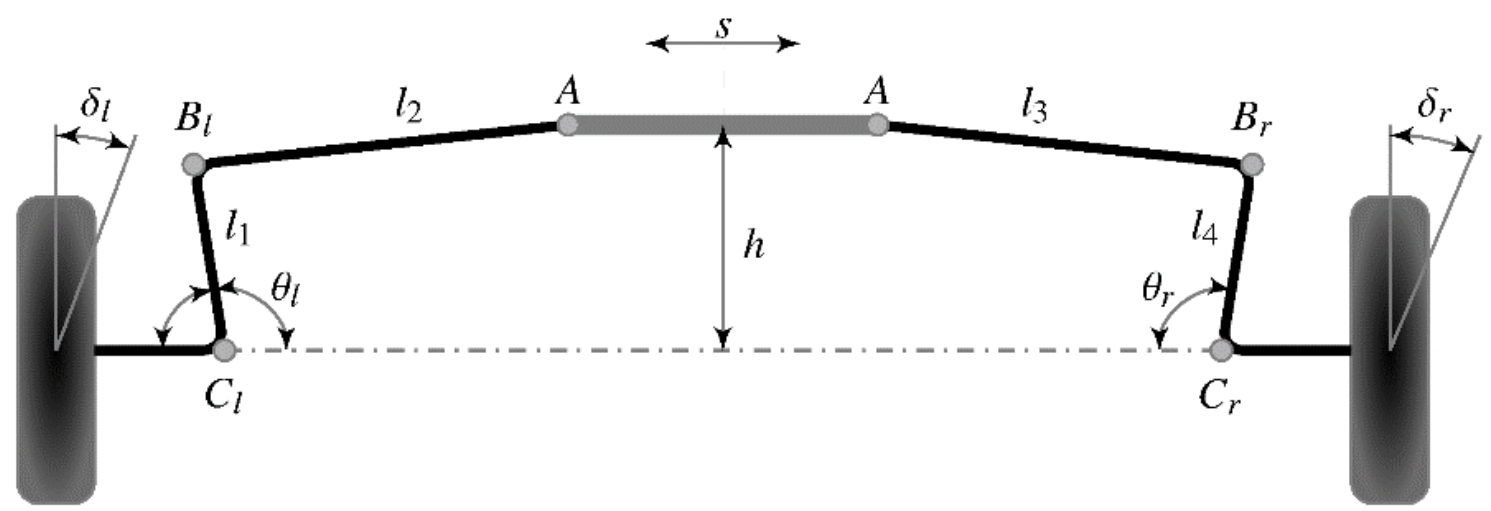

(a) 


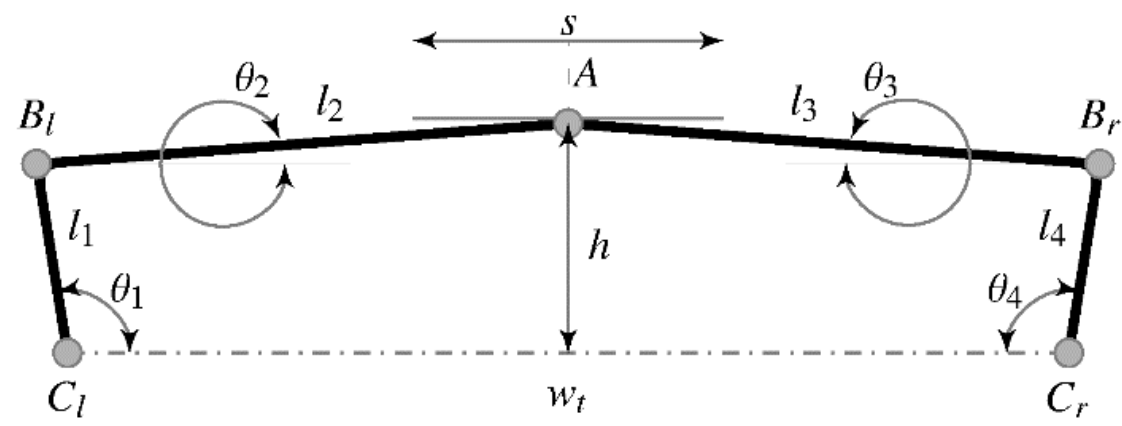

(b)

Figure 3. (a) and (b) kinematic modeling of rack and pinion steering linkage

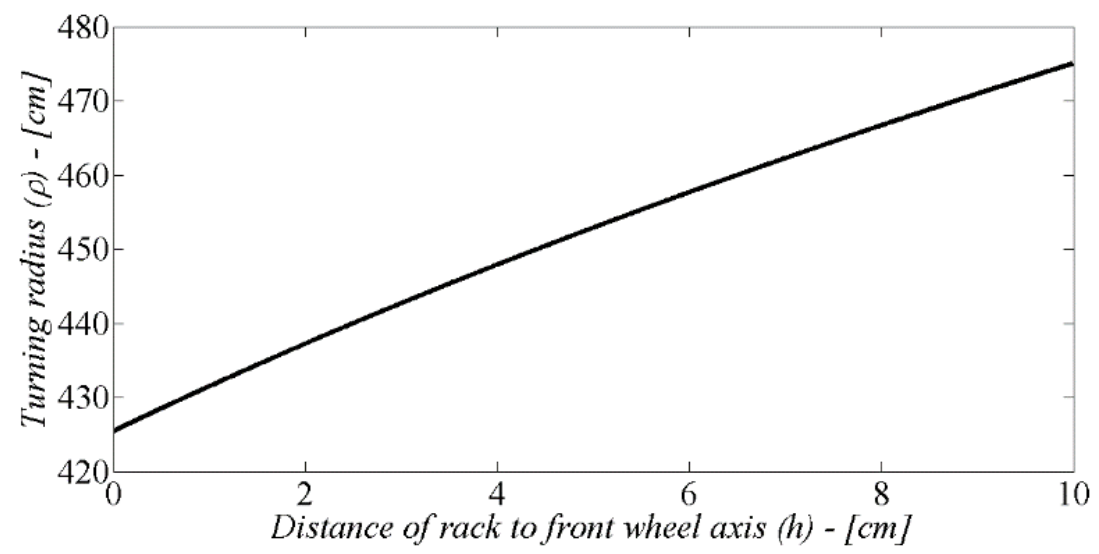

Figure 4. Turning radius for different rack placement

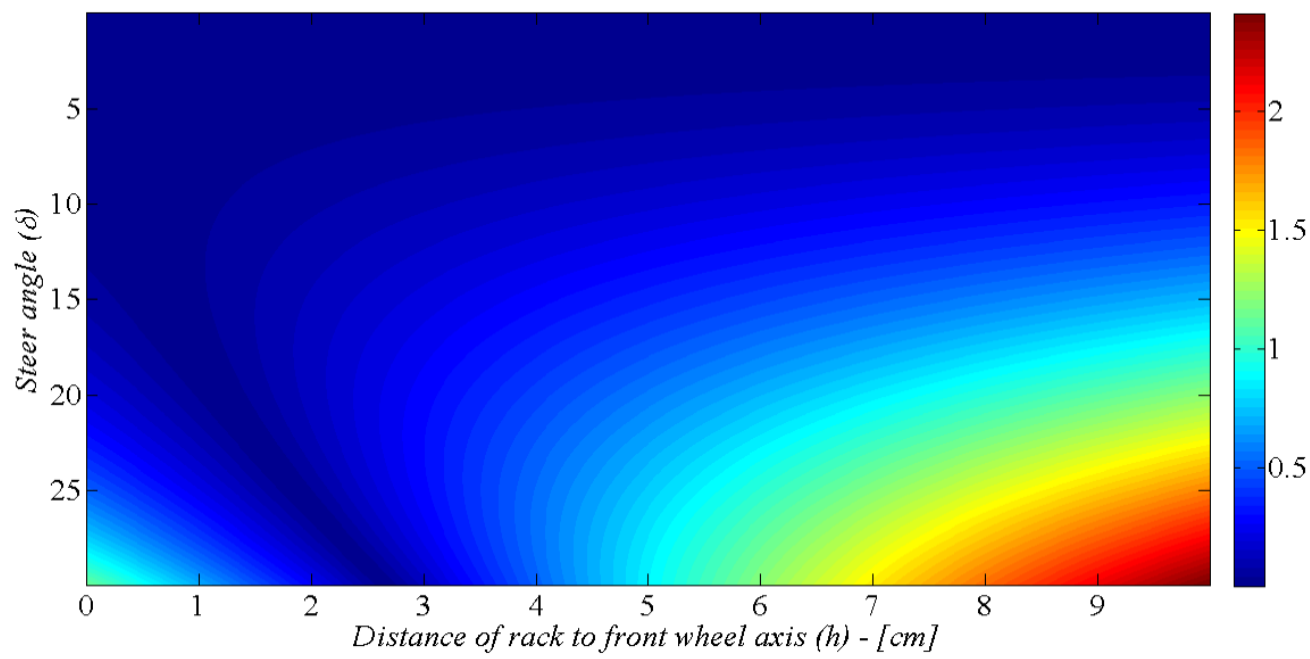

Figure 5. Steering error for different rack placement

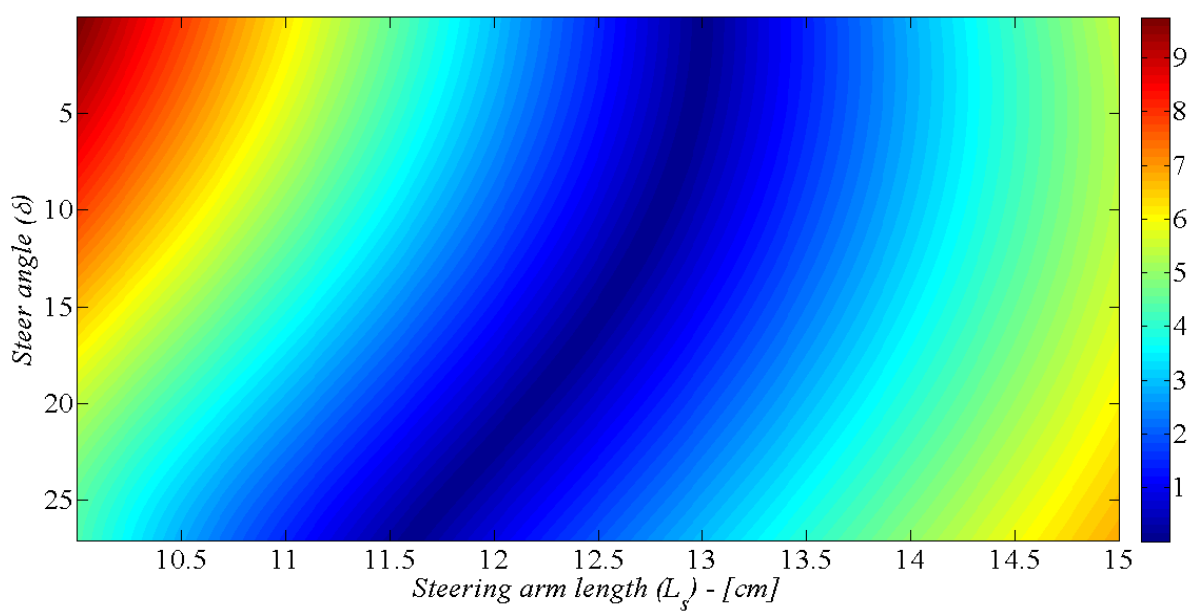

Figure 6. Steering error for different steering arm length 


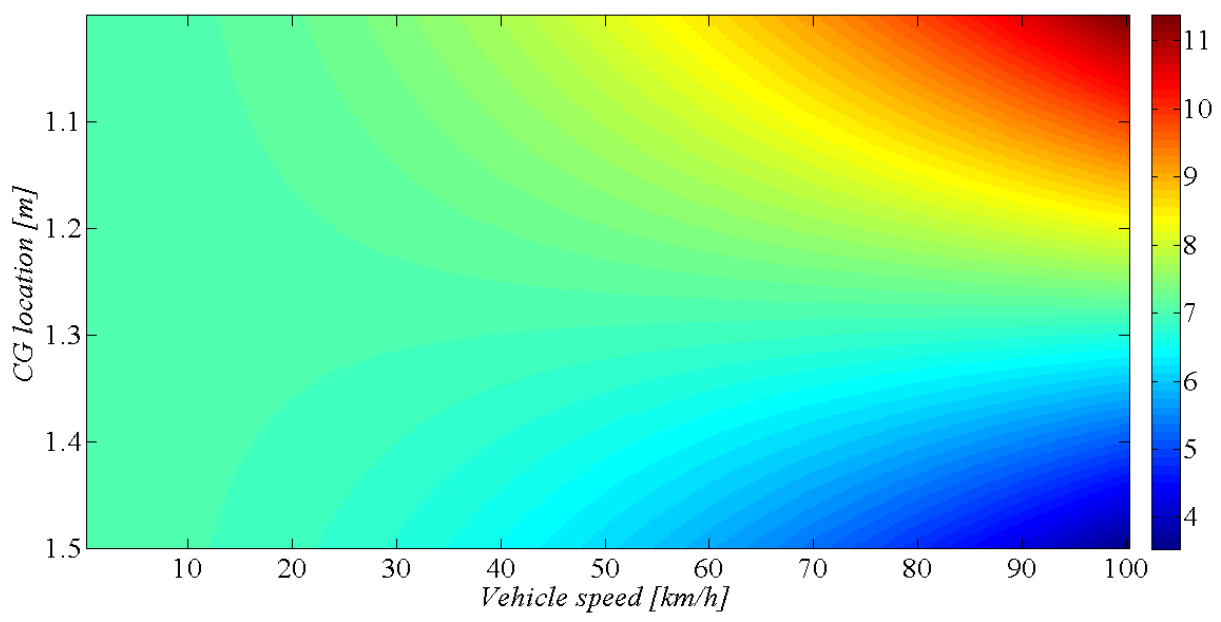

Figure 7. Turning radius for different center of gravity location

TABLE 1.

INITIAL DESIGN PARAMETERS

\begin{tabular}{|c|c|c|}
\hline Description & Notation & Value \\
\hline Wheel track & $W_{t}$ & $1490 \mathrm{~mm}$ \\
\hline Wheel base & $W_{b}$ & $2450 \mathrm{~mm}$ \\
\hline Rack length & $L_{r}$ & $560 \mathrm{~mm}$ \\
\hline Front wheel cornering stiffness & $K_{f}$ & $55000 \mathrm{~N} / \mathrm{m}$ \\
\hline Rear wheel cornering stiffness & $K_{r}$ & $60000 \mathrm{~N} / \mathrm{m}$ \\
\hline
\end{tabular}

